\title{
LA CARTA, FUENTE DE CONOCIMIENTO HISTÓRICO
}

\author{
Antonio MESTRE SANCHIS
}

Universitat de València

\begin{abstract}
Resumen
Para el historiador, los epistolarios se han convertido en una fuente de conocimientos de primer orden. En este artículo se valora la aportación historiográfica que han supuesto en el campo de la política, la cultura, la religión y la sociedad, el estudio de la correspondencia diplomática, las cartas cruzadas entre eruditos y literatos, o las familiares y confidenciales, y se aportan datos que demuestran que los epistolarios permiten abrir nuevos horizontes a la investigación histórica.
\end{abstract}

\begin{abstract}
Correspondence has become a primary source of knowledge for the historian. In this article the historical importance of its contribution, in political, cultural, religious and sociological fields, is assessed from correspondence between erudites and literary men, their families or those in their confidence, with a view to opening new avenues of investigation based on its content.
\end{abstract}

En una época dominada por el teléfono y el correo electrónico, resulta difícil comprender la importancia intelectual, social, literaria y política de la carta. Porque, dentro de la necesidad de comunicarse con otras personas, lejanas y separadas en el espacio, la carta adquirió la más variada gama de formas literarias.

En principio, una carta familiar llegó a convertirse en un modelo literario. Éste es, quizás, el caso de Cicerón que llegó a ser uno de los personajes clave en la evolución del género epistolar. $\mathrm{Y}$, desde el primer momento, surge la pregunta. Dado que Cicerón no utilizó el mismo estilo en las cartas que en los grandes discursos oratorios o en los tratados filosóficos, ¿el género epistolar permite un estilo más despreocupado y hasta desaliñado? Ésta será una duda que atormentará a humanistas e ilustrados que miran en el gran escritor latino el modelo literario a imitar. La solución teóricamente resultaba clara: una cosa es la difícil facilidad del estilo epistolar, que se elogiaba, y otra, muy distinta, el estilo vulgar y la negligencia literaria, que se rechazaba. 
Los grandes escritores de cartas eran conscientes de la dificultad que entrañaba el género epistolar como expresión de belleza literaria. En cualquier género, el autor escoge el campo que conoce bien, mientras en la carta el asunto le viene impuesto y no siempre tiene tiempo para la reflexión y el estudio. Gregorio Mayans, que escribió millares de cartas latinas y castellanas, aseguraba que el estilo epistolar debía asemejarse a la conversación de los hombres cuerdos, ni descuidado, ni demasiado pulido. No vale la afectación, decía, que algunos simulan, queriendo demostrar su conocimiento de las fuentes literarias más profundas, pero tampoco el estilo histriónico y desgarrado.

La dificultad radica en los múltiples aspectos a que el autor debe atender: persona a quien se dirige (dignidad o familiaridad), asunto de que se trata, adecuación a las circunstancias concretas, dentro de una coherencia que abarque el conjunto. Porque la carta sirve para alabar, expresar gratitud, manifestar alegría, formular lamentaciones, consejos, recomendaciones, para convocar, exhortar, consolar, pedir un favor, exponer un juicio o insinuar un proyecto.

Se comprenden los problemas para alcanzar la perfección en el género epistolar. El mismo Mayans lo manifestaba, al tiempo que no dudaba en confesar que nadie la había logrado. Nadie era perfecto, decía, y las deficiencias venían, o por la inutilidad de los argumentos, o los defectos de estilo. Aunque, en líneas generales, aconsejaba el estilo de los clásicos paganos, junto con la doctrina de los grandes Santos Padres. Y, aún después de exponer su juicio sobre el mérito de los grandes humanistas (de Erasmo y Vives a Manucio y Lipsio), insistía en que nadie era perfecto y todos tenían defectos que reprender.

Comprenderá con facilidad el lector que estos juicios se refieren explícitamente a la carta como género literario y, si queremos ser más precisos, a la epistola latina. Pero la carta abarca ámbitos mucho más amplios, desde la información diplomática -con cifra o sin ella- a la carta de amor y, sobre todo, aquella que incluye la noticia del suceso acaecido en la presencia del comunicante y transmitida al amigo o familiar que, por su lejanía, no puede conocer.

La valija diplomática se ha convertido, desde hace mucho tiempo, en una fuente de información política y, conservada en los grandes archivos de los Estados, ha constituido una fuente privilegiada en el conocimiento de las relaciones internacionales, del carácter de monarcas, Presidentes de las Repúblicas o Papas, y hasta de las circunstancias concretas que explican decisiones de alcance estatal, militar o eclesiástico. En este sentido, es conocida la habilidad de los embajadores de la República de Venecia en Madrid, o en Roma, y el valor de los informes que facilitaban las decisiones de la República con datos precisos y muchas veces exactos. Pero no menos interesante es la correspondencia diplomática que los embajadores alemanes enviaban a sus monarcas y que, en la parte correspondiente al siglo XVIII, ha sido publicada por Hans Juretschke.

En este sentido, sin disponer de toda la inmensidad de los fondos diplomáticos, los historiadores han hecho públicas algunas correspondencias especialmente interesantes para sus estudios. Como, por ejemplo, Ozanam sobre el intercambio epistolar 
entre el duque de Huéscar (embajador en París) con el Secretario de Estado José Carvajal. O la no menos interesante correspondencia de Nicolás de Azara, desde Roma, con los gobiernos españoles de Carlos IV que hizo pública Rafael Olaechea. Y, ya que hemos aludido a Nicolás Azara, ¿quién puede olvidar las chispeantes y agudas críticas del mundo romano en las cartas a su amigo y paisano Manuel de Roda, Secretario de Gracia y Justicia, y que son conocidas desde 1846 por la edición de El espíritu de D. Nicolás de Azara descubierto en su correspondencia epistolar con don Manuel de Roda? Y hasta un personaje que, por ser confesor del rey, tenía un carácter evidente de ministro de asuntos eclesiásticos de la monarquía, el P. Rávago, ha merecido la edición de su correspondencia con el embajador español ante la Curia Romana, cardenal Portocarrero, preparada por Carlos Pereyra y Pérez Bustamante. Y, sin abandonar el siglo XVIII, aunque en Europa, no podemos olvidar el interés por hacer pública la correspondencia del cardenal Tencin con el papa Benedicto XIV, o la amplísima de Tanucci, el famoso ministro de Carlos III durante su reinado en Nápoles. Y, en la misma línea, Ferrer Benimeli ha publicado, en tres volúmenes, La expulsión y extinción de los jesuitas según la correspondencia diplomática francesa. El título de la obra es suficientemnte expresivo de las fuentes y de la finalidad del estudio.

En la correspondencia diplomática existen muchos grados. Están, por supuesto, los informes de los embajadores o nuncios de la Santa Sede, a que hemos aludido. Pero existen otras cartas de menor relieve y que en el siglo XVIII español alcanzaron enorme importancia. Me refiero al sistema iniciado por Alberoni, conocido como vía de Estado, definido por William Coxe, como «un método particular de correspondencia llamado vía reservada, enviando los pliegos directamente al despacho del rey»'. Se trata de un medio de primer orden para el conocimiento de la política interna española del siglo XVIII, como lo han demostrado los estudios de Enrique Giménez y Pere Molas, entre otros. Ni que decir tiene que estos informes han contribuido a esclarecer aspectos diplomáticos, pero también asuntos políticos con implicaciones religiosas. Este es el caso de los problemas relativos a la expulsión de los jesuitas de España o de la actividad en las gestiones previas a la extinción de la Compañía. No hay duda de que los trabajos del Departamento de Historia Moderna de la Universidad de Alicante demuestran la importancia de semejante correspondencia. ${ }^{2}$

Ahora bien, existe otra clase de cartas políticas, unas veces públicas, otras privadas, que contribuyen a esclarecer aspectos importantes de las decisiones de los hombres de gobierno. Sin salir del siglo XVIII (objeto casi exclusivo del presente volumen), tenemos un ejemplo de las cartas públicas en la Carta-Dedicatoria de Mayans a Patiño en 1734, en la que proponía un plan de reforma cultural. Y, sin abandonar al mismo erudito, su correspondencia con el Fiscal de la Cámara del Consejo de Casti-

1. Texto en E. GIMÉNEZ LÓPEZ, Gobernar con una misma ley. Sobre la Nueva Planta Borbónica en Valencia, Alicante, Universidad, 1999, p. 20.

2. Sin afán de citar todos los trabajos, véase una de las últimas publicaciones, E. GIMÉNEZ LóPEZ (ed.), Expulsión y exilio de los jesuitas españoles, Alicante, Universidad, 1998. 
lla, Blas Jover, recientemente hecha pública, demuestra los recovecos de las polémicas regalistas entre el gobierno español y el nuncio del papa Benedicto XIV en la etapa que media entre los Concordatos de 1737 y 1753 . Y en idéntico sentido, la correspondencia cruzada entre el erudito y Agustín de Ordeñana demuestra el encargo del marqués de la Ensenada para que don Gregorio redactara las Observaciones al concordato de 1753, que después no permitió publicar ${ }^{3}$.

Desde otra perspectiva, la carta puede constituir un verdadero ensayo histórico o literario. En ausencia de revistas históricas, literarias, o científicas, la carta se convierte en la exposición, amplia y minuciosa, del criterio del autor sobre un tema histórico, obra científica o literaria, o simplemente, para exponer su propio pensamiento sobre el asunto más vario. Valga como ejemplo, en el aspecto literario, la carta de Mayans a Voltaire acerca del influjo de la obra de Calderón de la Barca, En este mundo todo es verdad y todo es mentira, sobre la tragedia Heraclius de Corneille.

En algún caso, la carta adquiere un carácter más universal y expresa la decisión de dar a conocer el criterio del autor sobre un tema cultural, político, social, religioso o literario. Éste es un género que adquiere múltiples facetas y del que conocemos ejemplos de alta calidad. Así por ejemplo, en las Cartas eruditas de Feijoo, dentro de la amplitud de temas estudiados, se vislumbra la idea crítica de la sociedad hispana del momento así como el interés del benedictino por expresar su criterio sobre la ciencia moderna (Newton, por ejemplo), su desprecio por la retórica, la sorpresa ante las noticias de los primeros trabajos de Rousseau (leídas en revistas literarias) o las esperanzas ante el inicio del reinado de Carlos III. Asimismo las Cartas familiares del jesuita exiliado Juan Andrés le permiten expresar sus experiencias ante el mundo cultural europeo.

Mayor calado político $-\mathrm{y}$, por supuesto, no menor alcance crítico y reformistapodemos vislumbrar en las Cartas persas de Montesquieu o en las Cartas marruecas de Cadalso. El mayor interés por conseguir una obra de estricta creación literaria no implica, en estos casos, un menor afán crítico social o político.

En contraste, gran parte de los trabajos de erudición de Mayans están redactados en forma de carta. Así, el Specimen bibliothecae hispano-maiansianae, aparecido en Hannover (1753), y que constituye una de las primeras exposiciones del humanismo hispano en Alemania, está expuesto en forma de carta latina al librero-impresor David Clement. Y, por supuesto, las grandes aportaciones del erudito de Oliva al conocimiento de la historia cultural española por parte de los hombres de letras europeos están redactadas en cartas, aparecidas en colecciones publicadas por el mismo Mayans, o incluidas en ediciones de Froben (Opera de Alcuino, 1779) o de Edward

3. G. MAYANS Y SISCAR, Epistolario. Mayans y Blas Jover, 2 vols., Transcripción, notas y estudio preliminar de Pere Molas, Valencia, Publicaciones del Ayuntamiento de Oliva, 1991 y 1995. Asimismo, el Epistolario Mayans y los altos cuadros de la magistratura y administración borbónicas, 3 vols., Transcripción, notas y estudio preliminar de A. Mestre y P. Pérez García, Valencia, Publicaciones del Ayuntamiento de Oliva, 1996-1998. 
Clarke en sus Letters concerning the Spanish Nation: Written at Madrid during Years 1760 and 1761 (Londres 1763).

En cualquier caso, las cartas de los grandes autores han interesado siempre a los historiadores. Este interés explica que el matrimonio Allen haya dedicado toda su vida a recoger y hacer públicas las Epistolae de Erasmo. O que Besterman, en relación con la Voltaire Foundation, hayan iniciado y continuado la gran empresa de publicar los volúmenes de Lettres de Voltaire. Constituyen, en ambos casos, una valiosísima fuente de noticias que permiten una profundización en el conocimiento del mundo literario de los humanistas, en el caso de Erasmo, y de los philosophes, en el caso de Voltaire. Nadie puede negar que, sin esas cartas, existirían muchos aspectos oscuros e inaccesibles al historiador. Y el experto podría sospechar qué hubiera sido de Erasmo y España (edición de México de 1966) de Bataillon sin las cartas del humanista de Rotterdam y de los erasmistas, o de la Filosofia e Política nel Settecento Francese (1962) de Furio Diaz, sin el epistolario de Voltaire.

Ahora bien, no todos los escritores de cartas son Erasmo o Voltaire. Pero muchos autores, que no pasan por paradigmas de la vanguardia intelectual y sólo suscitan el interés de los especialistas, aportan datos y noticias esenciales para el conocimiento de la evolución cultural. Este hecho explica que en los últimos años hayan visto la luz pública los epistolarios de una serie de hombres de letras que han esclarecido los caminos de difusion de las ideas así como de los contactos entre los hombres de letras. Sin afán de indicar todos los casos recientes, y sin salir del campo del humanismo, señalaré algunos de especial relieve.

Hace ya bastantes años, apareció la Correspondencia de Justo Lipsio con los españoles. Este interés resulta visible también en el extranjero, tanto en Holanda como en Italia. Así, por ejemplo, H. Bots publicó Correspondance de Jacques Dupuy et de Nicolaus Heinsius (1646-1656), en La Haya (1971); y más recientemente M. Sima ha hecho público el Epistolario de Jean Le Clerc (Florencia 1987). Pero quizás el síntoma del extraordinario interés suscitado por los epistolarios cruzados entre los hombres de letras sea el Inventaire de la correspondance de Johannes Fredericus Gronovius (1631-1671), aparecido en La Haya en 1974, debido al esfuerzo de P. Dibon, H. Bots y E. Bots-Estourgie. Con las recientes ediciones se mantiene una tradición que, desde los humanistas (especialmente Erasmo), ha continuado a lo largo de los siglos. Sin olvidar, por supuesto, el interés que han manifestado los historiadores italianos por conservar la abundantísima correspondencia de Ludovico Antonio Muratori, que, desde su cargo de bibliotecario del duque de Módena, mantuvo con los hombres de letras de toda Europa.

Ahora bien, eliminado, por supuesto, el carácter subjetivo del autor, la carta se convierte en un instrumento válido, y en muchos casos esencial, para conocer la vida cotidiana y social de una época. Pongo un ejemplo clarificador. Dentro del Epistolario mayansiano, publicado por el Ayuntamiento de Oliva, Antonio Mestre y Pablo Pérez Garcia han incluido, en tres volúmenes, la correspondencia de don Gregorio con los Consejeros de la monarquía borbónica. Además de la multiplicidad de asun- 
tos que aparecen en el frecuente cruce de cartas (temas agrarios, rencillas entre los pueblos vecinos, angustia por el uso y carestía del agua, abusos señoriales y protestas de los campesinos, efectos devastadores de la langosta, sistema de comidas, deficiencias sanitarias debidas al cultivo del arroz, problemas de competencias jurídicas o eclesiásticas...) hay una evidencia subyacente: el inmenso poder político de la judicatura a lo largo del siglo XVIII. Tenemos, por tanto, una serie de testimonios que amplian el conocimiento de la vida cotidiana del Siglo de las Luces, pero asimismo una prueba del alcance del poder de los jueces en la sociedad del Antiguo Régimen.

Esta visión del poder judicial en el siglo XVIII podría matizarse. Utilizando la división establecida por Fernández Albaladejo, y aceptada por Enrique Giménez, es muy posible que Mayans deseara tramitar todos sus asuntos dentro de una concepción de la monarquía judicial, y no por medio de los órganos que utilizaban el poder según la monarquía administrativa. Explicaría esta distinción el hecho de que, pese a su antigua amistad con Roda, don Gregorio se dirigiera preferentemente, en sus conflictos, a un recién conocido como era Campomanes, o a Colegiales como Velasco que estaba dentro del cuerpo judicial. Es posible, por supuesto, que el erudito de Oliva no pensara conseguir sus pretensiones por la vía de Estado, donde siempre encontró obstáculos, desde Patiño a Carvajal. No se olvide que Mayans pertenecía a una familia austracista.

Pero la mayoría de las cartas eran el medio para comunicar e intercambiar noticias personales, literarias, políticas o sociales. En una época, en que no existían periódicos diarios, ni revistas periódicas, y sólo llegaban las noticias por medio de los Mercurios o Gacetas, más o menos oficiales, las noticias comunicadas por los protagonistas directos, o testigos presenciales, superada la visión parcial que pudiera darse, se convierten en una fuente de conocimientos. Por supuesto, es necesario contrastar los datos aportados con los procedentes de otras fuentes, pero resultan muy clarificadores para comprender la actitud del personaje que expresa su criterio, las circunstancias en el desarrollo de un suceso o las causas que motivan las decisiones personales.

Más aún, las cartas privadas -más o menos confidenciales- permiten esclarecer las relaciones de amistad o antipatía entre individuos o grupos, tanto en el campo político como en el cultural. He aquí algunos ejemplos clarificadores. En carta confidencial, después de afirmar que Mayans le había dicho ser el autor de la Ortografía castellana de Bordazar, escribía Feijoo las siguientes palabras: «Es excusado remitirme dichas obras (de Mayans) que para nada pueden servir. Sin embargo del sumo desprecio que merecen sus escritos, le complací los días pasados, escribiendo una carta de favor al conde de Carlet» ${ }^{4}$. La correspondencia conservada explica el proceso de relaciones entre los dos ilustrados. Mayans escribió una carta castellana al mismo Feijoo, señalando los errores históricos que había descubierto en los discursos titulados Glorias de España, incluidos en el Teatro crítico. También tenía preparada

4. Texto en V. PESET, Gregori Mayans i la cultura de la Il-lustració, Barcelona-Valencia, Edicions 62Tres i quatre, 1976. 
una carta latina que pensaba incluir en Epistolarum libri sex (1732). Era una amenaza que no gustó al benedictino, que se vio obligado a reconocer que nunca Mayans le había confesado ser el autor de la Ortografía castellana del impresor Antonio Bordazar $^{5}$.

Más todavía. Es bien sabido que el erudito de Oliva, después de abandonar la Real Biblioteca, contrajo matrimonio en 1740. Según puede deducirse, constituyó una sorpresa en el mundo intelectual, al menos entre los clérigos. Marañón, en Ideas biológicas del P. Feijoo (p. 270), transcribe unas palabras muy expresivas: «Bien he reído e hice reir a otros con la carta sobre el matrimonio de Mayans». Los textos transcritos expresan una animosidad soterrada del benedictino, no sólo respecto a la obra intelectual del joven erudito, sino también de la persona en decisiones tan íntimas como el matrimonio como forma de vida. Pero, si a esas palabras añadimos los comentarios del P. Flórez, lamentando «el casamiento de Mayans, pues dice que el estudio no quiere diversiones, y que el matrimonio sirve de obstáculo para las letras ${ }^{6}$, podemos llegar a la aproximación del concepto que tenían los religiosos -en este caso, de alto nivel intelectual- respecto al matrimonio en personas dedicadas al estudio.

Por supuesto, también el fondo epistolar mayansiano explica muchos matices de las relaciones intelectuales del XVIII, y en concreto respecto a Feijoo y Flórez. Si las cartas dirigidas a Feijoo, antes aludidas, explican su criterio sobre los escasos conocimientos históricos del benedictino, en otras ocasiones rebate los supuestos de Feijoo sobre el escaso o nulo valor de la Retórica en la formación del estilo personal. Y en cuanto a Flórez, la correspondencia cruzada entre el autor de la España sagrada y el erudito de Oliva demuestra su colaboración inicial y las razones de la posterior ruptura, basada tanto en el desprecio del agustino a la teoría mayansiana sobre la Era Hispánica, como en las divergencias sobre los orígenes del cristianismo en España. Porque, frente a la postura complaciente de Flórez respecto a las tradiciones jacobeas (venida de Santiago,Virgen del Pilar, Varones Apostólicos...), Mayans tomó una actitud crítica, negando todas esas tradiciones por carecer de base documental. Todos esos matices sólo han sido posibles gracias al conocimiento de la correspondencia personal entre los protagonistas y los amigos que participaban de idénticos criterios.

En consecuencia, podemos afirmar que los epistolarios constituyen un medio muy importante para conocer la evolución intelectual de muchas personalidades del siglo XVIII. Y no sólo en España. Al analizar Fabrizio Lomonaco las diferentes interpretaciones de la personalidad intelectual de Vico, se plantea el problema de la evolución del pensamiento del filósofo napolitano. He aquí sus interesantes palabras: «In un mondo complesso quale fu la Napoli tra il XVII e il XVIII secolo si deve tener conto anche della "tradizione orale" o solo manuscritta e clandestina, dei frequenti di-

5. El mismo Peset publica la carta latina de Mayans. La carta castellana en A. MESTRE SANCHIS, El mundo intelectual de Mayans, Valencia, Publicaciones del Ayuntamiento de Oliva, 1978.

6. Texto en A. MESTRE SANCHIS, Historia, fueros y actitudes políticas. Mayans y la historiografía del XVIII, Valencia, Publicaciones del Ayuntamiento de Oliva, 1970, p. 374. 
battiti e scritti accademici, delle più modeste opere de divulgazione, dei numerosi "giornali" eruditi, nonché del grande "commercio" epistolare privato, tutti veicoli, questi, di informazioni spesso inattese»" ${ }^{7}$. Y podemos completar el paralelismo. ¿Qué sabríamos de la evolución intelectual de Mayans sin la correspondencia del erudito con Manuel Martí el deán de Alicante? Y si Lomonaco hablaba del influjo de Grocio en el pensamiento de Vico, ¿qué podríamos hablar de los consejos del Deán para que el joven erudito leyera Nicolás Antonio, Du Cange, Bacon o Mabillon, entre otros?

En este sentido, es preciso tener en cuenta la provisionalidad del conocimiento histórico. Nadie podía sospechar de dónde procedía el criterio tan ajustado a la historia del derecho español demostrado por Andrés Marcos Burriel. Los estudios de teología del jesuita no propiciaban la riqueza de noticias ni la exactitud de juicio manifestada en la carta a Juan José Ortiz de Amaya. Sólo la correspondencia de Burriel con Mayans, recientemente hecha pública ${ }^{8}$, ha venido a demostrar el origen de los conocimientos jurídicos del jesuita, así como sus ideas reformistas expuestas en sus Apuntamientos, publicados por Echánove. Se trata de los planteamientos mayansianos que Burriel amplió en los años de investigación en el archivo de la catedral de Toledo, como se trasluce en las cartas al ministro José Carvajal y al P. Rávago.

Por lo demás, la dependencia y el intercambio cultural -muchas veces imperceptible o muy difícil de precisar en las obras literarias o eruditas- resulta evidente por medio de la correspondencia personal. Aludía antes a la influencia de Manuel Martí en la formación intelectual de Mayans. Se podía intuir por las cartas del Deán incluidas en las latinas de don Gregorio o en el hecho de que, siendo bibliotecario real, el erudito de Oliva publicara Epistolarum libri duodecim de Martí (1735). Pero sólo la publicación de las cartas castellanas, mucho más familiares y confidenciales, ha permitido conocer el alcance del influjo de Martí en la actitud cultural de don Gregorio ${ }^{9}$. $\mathrm{Y}$, en el mismo sentido, la abundantísima correspondencia de Mayans conservada ha permitido precisar una poderosa corriente humanista que recorre el siglo XVIII hispano, desde Martí a Cerdá Rico y Pérez Bayer, pasando por el intermedio de don Gregorio, que lo amplió al grupo sevillano y a los jesuitas de Cervera del entorno de José Finestres.

Muchas veces, los epistolarios contribuyen a conocer en profundidad el funcionamiento de las instituciones. Así resultaría muy difícil conocer la intimidad de la Real Biblioteca en el XVIII, sin las cartas semanales y llenas de afecto y sinceridad que escribía el bibliotecario Martínez Pingarrón a su amigo y confidente Gregorio Mayans. Las cartas vienen a confirmar el poder del confesor del monarca antes de la reforma de 1761. Porque el P. Robinet, confesor de Felipe V, que propició la creación

7. F. LOMONACO, Lex Regia. Diritto, Filologia e Fides historica nella cultura politico-filosofica dell'Olanda di fine Seicento, Napoli, Studi Vichiani, 19, 1990, p. 15.

8. G. MAYANS Y SISCAR, Epistolario II, Mayans y Burriel, Transcripción, notas y estudio preliminar de A. Mestre Sanchis, Valencia, Publicaciones del Ayuntamiento de Oliva, 1972.

9. G. MAYANS Y SISCAR, Epistolario III, Mayans y Martí, Transcripción, notas y estudio preliminar de A. Mestre Sanchis, Valencia, Publicaciones del Ayuntamiento de Oliva, 1973. 
de la Real Biblioteca, tenía el poder omnímodo en la elección de los bibliotecarios y en el funcionamiento de la institución. Y en la misma línea, los jesuitas confesores de los reyes (Robinet, Daubenton, Clarke, Fèvre o Rávago) fueron los responsables de los aciertos -0 de los errores- en los nombramientos, de la ausencia de proyectos de largo alcance, pero también del apoyo -y posterior abandono- a los redactores del Diario de los literatos de España y de los ambiciosos proyectos del P. Rávago, centrados en la Bibliotheca arabico-hispana escurialensis de Miguel Casiri, de Regiae matritensis bibliothecae manuscripti graeci de Juan de Iriarte o la reedición de la Bibliotheca Hispana de Nicolás Antonio aunque aparecieran cuando el jesuita ya había sido exonerado del confesonario regio. La correspondencia de Martínez Pingarrón viene a confirmar y esclarecer la historia de la Real Biblioteca y así lo ha reconocido su reciente historiador García Ejarque, que utiliza con profusión los datos proporcionados por Pingarrón.

Dos nuevos aspectos quisiera señalar en el uso de los epistolarios: unas veces, vienen a corregir afirmaciones y juicios muy extendidos; otras, vienen a abrir nuevos campos en los estudios históricos. Existen, y probablemente existirán siempre, una serie de juicios mantenidos por historiadores responsables y, en general, aceptados por la comunidad científica, pero que, en realidad, son erróneos. Este es el caso de Ballesteros Beretta que, al estudiar la figura de Juan Bautista Muñoz, cronista de Indias y creador del Archivo de Indias, escribía con cierta circunspección: «A propósito del valencianismo, Iturri esgrime a su favor la opinión de Mayans, insigne valenciano, muerto en 1781, y que según parece no tuvo trato alguno de amistad con nuestro Muñoz» ${ }^{10}$. Este juicio ha resultado rebatido con rotundidad por la correspondencia privada. Muñoz fue profesor de matemáticas de un hijo de Mayans, asistía a las tertulias del erudito de Oliva y frecuentaba su biblioteca y solicitó de don Gregorio el préstamo de dinero para trasladarse a la Corte. Por lo demás, el mismo cronista de Indias confesó, en carta al anciano don Gregorio, cuánto le debía: «Esté Vm. persuadido a que, entre tantos como deben a Vm. el desengaño, el buen gusto, el conocimiento de libros y otras instrucciones, acaso no habrá uno, ni más afecto a Vm., ni más agradecido. $\mathrm{Y}$ deseo, y aun ruego a $\mathrm{Vm}$., que me proporcione ocasiones para acreditarlo»" ${ }^{11}$.

Otros errores se corrigen con los datos aportados por la correspondencia. Así, Jean Guéhenno, en su conocida biografía Jean-Jacques Rousseau (1962), al leer la serie de epistolarios pertinentes, entre ellos las cartas del mismo Rousseau, llegó a la convicción de los errores esparcidos en sus Confesiones. He aquí sus palabras: «Acababa de leer todo lo que entonces había aparecido de la correspondencia de Rousseau en la bella edición de Theóphile Dufour. A medida que avanzaba en su lectura, crecía

10. A. BALLESTEROS BERETTA, Don Juan Bautista Muñoz. La Historia del Nuevo Mundo, en Revista de Indias, III, 10 (1942) p. 641.

11. 26-III-1770. Texto en A. MESTRE SANCHIS, Historia, fueros y actitudes políticas. Mayans y la historiografía del XVIII, Valencia, Publicaciones del Ayuntamiento de Oliva, 1970, p. 330. 
en mí el sentimiento de que su vida no fue la que él mismo había creído, la que había contado en las Confesiones con probidad ejemplar. No conseguía explicarme mi sentimiento con razones simples y claras. Posiblemente sea porque uno nunca se conoce a sí mismo, porque nuestra vida, tal como la vivimos, siempre es diferente a nuestra vida, tal como la recordamos. Sentí que los errores de Jean-Jacques dependían del detalle mismo de su relato. Decidí buscar esos errores, comentar sus Confesiones página por página, mejor aún, reescribirlas, tal como lo permitían innumerables documentos y particularmente la correspondencia». Por mi parte, si se me permite una aportación personal, puedo afirmar que, sin la enorme masa de correspondencia personal de Mayans, me hubiera sido imposible conocer la peripecia vital del erudito de Oliva, y el epistolario ha sido la base de la biografía recientemente publicada.

La gratitud confesada por Muñoz no fue óbice para que, en vista de las circunstancias que le rodeaban, escogiera el favor de Pérez Bayer, mejor situado en la Corte, en detrimento del destino proyectado por Mayans. Porque la correspondencia privada demuestra que don Gregorio, por medio de Felipe Samaniego, director provisional de los Reales Estudios de San Isidro y criatura de Rodríguez Campomanes, consiguió el nombramiento de Muñoz como profesor de Retórica en los Reales Estudios. Este hecho explica la sorpresa de Simón Díaz, que no comprendía el nombramiento de Muñoz, sin haber opositado a la cátedra. Pero la propuesta de Bayer le resultó más atractiva y Muñoz fue nombrado cosmógrafo mayor de Indias y años después cronista y encargado de responder a la Historia de América de Robertson. Claro que, también en este caso, está la mano protectora de Bayer, hombre de confianza del Secretario de Gracia y Justicia Manuel de Roda. De nuevo la correspondencia privada viene a clarificar algunos problemas políticos. En el caso del nombramiento de Director de los Reales Estudios de san Isidro, Bayer, con el apoyo de Roda, impuso su candidato (Manuel de Villafañe) en detrimento del propuesto por Campomanes (Samaniego). Lo mismo ocurrió respecto a la Historia de América de Robertson, que deseaba traducir Campomanes desde la Real Academia de la Historia, que era cronista de Indias, mientras Bayer impuso su candidato, de nuevo Juan Bautista Muñoz. Estas circunstancias vienen a clarificar la oposición sistemática de Campomanes y de la Real Academia de la Historia contra la actividad de Muñoz en sus estudios sobre la historia de América. Y, en el fondo, la correspondencia privada explica muchas divergencias entre Campomanes y Roda, que no siempre coinciden en sus planteamientos reformistas, al menos en los nombramientos de personas para llevar a cabo las reformas propuestas $^{12}$.

Estas últimas referencias nos demuestran que los epistolarios permiten abrir nuevos horizontes a la investigación histórica. Empiezo, con el fin de fundamentar la veracidad de este juicio, con el testimonio del mencionado Lomonaco. Después de indi-

12. Estos aspectos pueden seguirse en el estudio preliminar de G. MAYANS Y SISCAR, Epistolario VI. Mayans y Pérez Bayer, Transcripción, notas y estudio preliminar de A. Mestre Sanchis, Valencia, Publicciones del Ayuntamiento de Oliva, 1977. 
car la importancia del «rapporto epistolare privato», en los siglos XVI y XVII como medio de información literaria, asegura con rotundidad: «La lettera, espressione tangibile di collaborazione scientifica, diventa, infatti, uno strumento efficace per la diffusione di notizie letterarie, scientifiche ed erudite, per lo scambio di utili favori, quali la collazione di manoscritti o la consultazione e la copia di codici originali, mostrando con ciò anche il grado di interesse suscitato dalle coeve indagini e publicacioni» (p. 42)

El juicio del historiador italiano está basado en la experiencia personal. En su estudio sobre las relaciones culturales italiano-holandesas en el XVII, la correspondencia de Gronovio -que, a su vez, había sido el editor de las Epistolae de Casaubon- le permite establecer una densa red de intercambios culturales entre las grandes figuras de la República de las Letras: Heinsius, Salmasius, Graevius, Grocio, G. J. Vosio, Scioppio... (No deja de constituir un síntoma revelador que la mayoría de la correspondencia de los autores citados -editada en el siglo XVII e inicios del XVIII- era bien conocida por Mayans, como demuestra su prólogo a Epistolarum libri sex de 1732). Este intercambio epistolar de Gronovio le permite a Lomonaco aseverar con rotundidad que, para el conocimiento de la importancia cultural de la residencia de Gronovio en Italia, los manuscritos autógrafos de los eruditos hallados en las ciudades visitadas, es «accanto all'epistolario, una fonte imprescindibile, capace di illuminare il senso di certi riferimenti e richiami appena intravisti, di confortare o smentire progetti e tendenze di ricerca» (p. 46).

Idéntico juicio podemos formular respecto al movimiento cultural del XVIII español. He aludido antes a la influencia del deán Martí en las lecturas del joven Mayans, entre cuyos autores están, en abundancia, los citados escritores holandeses del XVII. No puedo menos de aludir con la máxima brevedad al austracismo de la familia del erudito de Oliva, conocido sólo por la correspondencia privada, que explicaría, en gran parte, la marginación política que sufrió por parte de los distintos gobiernos españoles, de Patiño a Carvajal, pasando por el P. Rávago. Este hecho vendría a permitirnos comprender las razones de su aislamiento, pero también la causa de su nombramiento de bibliotecario real por medio del cardenal Álvaro Cienfuegos, jesuita exiliado por austracista, que consiguió el nombrameinto por medio del confesor de Felipe V, el jesuita Guillermo Clarke.

Pero prefiero señalar la trascendencia de la correspondencia conservada para cambiar, en cierta medida, alguna visión unilateral del movimiento ilustrado español. Dada la importancia del influjo de los filósofos franceses en la ilustración española -innegable, por lo demás-, conviene observar otras relaciones culturales de nuestros hombres de letras del XVIII con intelectuales de otras naciones. En este sentido, los epistolarios privados son un instrumento muy importante de clarificación. He aludido antes a las cartas de los humanistas españoles con Erasmo. Pero podría verse la continuidad de este intercambio, como podrían ser nuestros corresponsales con Lipsio, el intercambio epistolar de Mondéjar con el jesuita belga Papebroek (principal artífice de Acta sanctorum de los bolandistas) y con el bibliotecario e historiador francés 
Etienne Baluze, o la correspondencia de los benedictinos de la Congregación de Valladolid (a la que pertenecían el cardenal Sáenz de Aguirre, Feijoo y Sarmiento) con los maurinos de Saint Germain des Près, entre los que sobresale Jean Mabillon, como ha demostrado Dubuis. En esta misma línea de continuidad podemos recordar la correspondencia del Deán de Alicante con Montfaucon, el maurino editor de los Santos Padres griegos, o con el jurista italiano Gravina.

Finalmente, el epistolario mayansiano ha permitido conocer una fuente insospechada de intercambio cultural con Europa. Países, generalmente marginados en la visión general del movimiento ilustrado hispano, como Holanda, Suiza, Alemania, Italia, Inglaterra o Portugal, adquieren un mayor relieve en el conjunto de nuestra ilustración. Ediciones en Holanda, tanto de nuestra pasado como la Historia latina del P. Mariana con la continuación del trinitario valenciano Miñana, como de los escritores coetáneos, el De bello rustico valentino sobre la Guerra de Sucesión en España del mismo Miñana o los tratados jurídicos del erudito de Oliva, bien acogido entre los hombres de letras de los Países Bajos.

En este sentido, adquiere especial relieve, la correspondencia privada entre Mayans y Meerman, jurista, político y hombre de negocios holandés, que se convirtió en el introductor de la cultura hispana en Europa a través de Mayans, que proporcionó las obras -impresas y manuscritas- de nuestros grandes juristas, que aparecieron en Novus thesaurus iuris civilis et canonici, impresos por el prestigioso Pierre D'Hondt. Más aún, Meerman presentó a Mayans a los miembros de la Academia Latina de Jena, que lo nombraron socio de la docta institución; al impresor de Hannover, David Clement, que se apresuró a publicar el catálogo de la biblioteca mayansiana, con el título de Specimen bibliothecae hispano-maiansianae (1753); al profesor del liceo de Osnabrück, Strodtmann, autor de una biografía alemana de Mayans en 1746 y que prestó su nombre a la autobiografía aparecida con el título de Gregorii Maiansii, generosi valentini, vita (Wolffenbütel, 1756). Pero quizás la más importante conexión debida a Meerman fue la correspondencia con los editores Cramer de Ginebra, que le enviaron las obras completas de Voltaire y le propiciaron la correspondencia con el señor de Ferney, así como la Enciclopedia y El espiritu de las leyes de Montesquieu. Asimismo Meerman propició la relación de Mayans con el editor de Lucca, Rochi, que permitió al erudito de Oliva ampliar su biografía de Antonio Agustín y colaborar de manera muy positiva en la edición de Opera omnia del famoso arzobispo de Tarragona. Con ello, el erudito de Oliva venía a completar sus buenas relaciones con Italia, iniciadas con el influjo de Martí, continuadas con la correspondencia directa con Muratori, y finalizadas con la colaboración con el editor Rochi.

Pues bien, toda esa peripecia intelectual sólo ha sido conocida gracias a la correspondencia privada. Son matices, podrá decirse. Es cierto, pero son matices importantes y clarificadores de una actitud intelectual y de unas corrientes culturales que merecen ser analizadas. No podemos permanecer en el tópico -por importante que sea- de la dependencia hispana de la ilustración francesa. El mundo cultural de nuestros hombres del XVIII fue más rico de lo que a primera vista se vislumbra. Nuestros 
hombres de letras abrieron sus tentáculos al mundo europeo - de Inglaterra a Italia, de Alemania a Portugal (no olvidemos la importancia del mundo de Pombal y de sus colaboradores, de Villasboas a Pereira), de Suiza a Holanda- y, sobre todo, establecieron entre ellos unas redes de intercambios culturales, de complicidades y divergencias, que nos permiten comprender las ansias religiosas, políticas, económicas o sociales que animaban sus inteligencias, sus preocupaciones más íntimas o sus aspiraciones más profundas. $\mathrm{Y}$ este descubrimiento es muy importante para comprender nuestro pasado histórico en todos los aspectos.

Quisiera añadir unas palabras sobre un campo nuevo, apenas aludido en esta presentación. También los problemas teológicos, en sus aspectos más complejos, adquieren nueva luz a través de la correspondencia. Un primer caso puede verse en la correspondencia del obispo de Barcelona, José Climent, relativas a la Iglesia cismática de Utrecht. Las cartas contribuyen a clarificar todo el proceso sufrido por el obispo. Su Pastoral sobre la Iglesia de Utrecht, aparecida con la traducción de las Costumbres de los israelitas y de los cristianos de Claude Fleury, provocó un escándalo. El mismo papa Clemente XIV, tan sumiso a las directrices de los Borbones hasta la extinción de la Compañía, escribió a Carlos III, solicitando un examen de la Pastoral. Los fiscales del Consejo y el Consejo Eclesiástico analizaron el documento. Climent salió absuelto, pero sólo las cartas conservadas explican el proceso en su amplitud y las razones de la absolución. El Consejo Eclesiástico apoyó la actitud del obispo de Barcelona. Sólo después de la seguridad de semejante favor, Climent dio el paso de escribir en 1770 a Clemente XIV en favor de la Iglesia cismática. Por lo demás, el proceso sirvió para que Roda intercediera por la iglesia de Utrecht ante las autoridades romanas ${ }^{13}$.

Más profundas en el campo teológico son las noticias propiciadas por la correspondencia de los protagonistas belgas. En el fondo, para entender el origen y proceso del cisma de esta Iglesia, resulta esencial la correspondencia del cabildo de Utrecht. Más aún, una carta del teólogo Opstraet, profesor de Lovaina, expresa con claridad la idea de Van Espen sobre el origen de la autoridad del cabildo para elegir al obispo de Utrecht. Y hasta el mismo Van Espen explicaba en una carta la distinción que, a su juicio, existía, entre la obligatoriedad de obediencia de los fieles respecto a una definición dogmática del Concilio de Trento y la actitud ante una bula dogmática como la Unigenitus de Clemente $\mathrm{XI}^{14}$

Hemos podido observar la importancia de los epistolarios en cuatro campos: político, literario, religioso y aun social. Finalizadas estas palabras de presentación, acabo de recibir el Catalogue 1999/2000 Supplement de la Voltaire Foundation, editado por la Universidad de Oxford. Y no ha dejado de sorprenderme que, entre las recien-

13. Esta correspondencia es la base de la Tesis de Licenciatura de J. LLIDÓ HERRERO, presentada en Ia Facultad de Teología de Valencia en 1997, con el título de El obispo Climent en los Escritos inéditos del Archivo General de Simancas, y publicada en la revista Anales Valentinos de dicha Facultad.

14. El uso de esta correspondencia puede verse en G. LECLERC, Zeger-Bernard van Espen (1646-1728) et l'autorité ecclésiastique, Zurich, 1964. 
tes publicaciones sobre el siglo XVIII en él indicadas, aparezcan varios volúmenes de correspondencias. Y, como era de esperar, sobresalen, las diplomáticas, literarias y familiares, y hasta religiosas. Entre las primeras, pueden verse, Louis XVI and the comte de Vergennes. Correspondance, 1774-1787, y Correspondance de Frédéric II avec Louise Dorothée de Saxe-Gotha, 1740-1767. En el campo literario, aparecen Correspondance de Pierre Bayle (tomo I, 1662-1674), el volumen XVIII de Oeuvres complètes de Montesquieu, Correspondance I (1700-1731); y el volumen LII, con el que finaliza, con su Index général, la Correspondance complète de Jean Jacques Rousseau. Finalmente, en el campo más familiar, podemos ver la referencia al volumen VI de la Correspondance de Mme. de Graffigny. Además, claro está, de los estudios centrados en los epistolarios, como La Bible dans la correspondance de Voltaire de François Bessire, o el colectivo de varios autores sobre Femmes en toutes lettres: les épistolières du XVIII siècle. $\mathrm{Y}$, sin salir de España, es menester confesar que las ponencias presentadas al Congreso Internacional sobre Gregorio Mayans, (mayo 1999), con motivo del III Centenario de su nacimiento, de reciente aparición, no hubieran alcanzado el alto nivel intelectual, sin el conocimiento del inmenso epistolario mayansiano.

El lector encontrará en este volumen una serie de análisis de diversos epistolarios. Podrá observar ejemplos de relaciones diplomáticas de alto nivel, como el trabajo de Gaetano Cerchiello sobre la correspondencia de Tanucci con Grimaldi, el ministro de Estado de Carlos III, con el Monitorio de Parma como tema de fondo, o los datos sobre el Cónclave en que se eligió a Clemente XIV, estudiados por Francisco Belmonte, o la política napolitana en la correspondencia entre el Secretario de Estado vaticano Torrigiani y los nuncios de Madrid. También podrá seguir la importancia de la correspondencia de carácter privado y de índole cultural remitida desde París a Manuel de Roda por el Secretario de la embajada de Aranda, el también aragonés Ignacio de Heredia, que analiza Jesús Pradells. Y, finalmente, también hay un ejemplo de cartas familiares, nada menos que del científico alicantino Jorge Juan, preparada por Armando Alberola y Rosario Die.

Se trata, por tanto, de un elenco de epistolarios que, analizados por diversos autores, pueden contribuir a manifestar la importancia de las cartas. Unas, importantes y escritas con intenciones políticas o literarias. Otras, redactadas con la mayor sencillez, dentro de un ambiente familiar y de amistad. Pero, en todos los casos, constituyen un importante testimonio de nuestro pasado. 